\title{
Estudo em gêmeos sobre fatores individuais e familiares de risco para exposição a trauma e transtorno de estresse pós-traumático
}

Koenen K., Harley R., Lyons M. et al. A twin registry study of familial and individual risk factors for trauma exposure and posttraumatic stress disorder. Journal of Nervous and Mental Disease 190: 209-18, 2002 Comentado por Andréa Machado Vianna ${ }^{l}$

Recebido: 19/5/2003 Aceito: 5/6/2003

Os seguintes fatores influenciam a avaliação de um evento, como traumático e de risco para o desenvolvimento de transtorno de estresse pós-traumático (TEPT): a característica do trauma, a avaliação da experiência traumática ameaçando a integridade física do indivíduo, o gênero, a idade, a dependência química e a existência de transtornos psiquiátricos anteriores ao trauma.

O mecanismo de interferência da história familiar no desenvolvimento de TEPT não está claro e sua importância subestimada na literatura. Observando esta lacuna, os autores do presente registro se propuseram a pesquisar, em gêmeos do mesmo sexo, a associação de fatores de risco individuais e familiares que influenciam na exposição ao trauma e no posterior desenvolvimento de TEPT; avaliaram também, a influência de psicopatologia anterior ao trauma, tanto no aspecto individual como familiar.

Os dados de 6.744 indivíduos gêmeos do sexo masculino, participantes do serviço militar durante a Guerra do Vietnã, foram analisados quanto aos seguintes aspectos: dependência química; dados sociodemográficos; exposição a eventos traumáticos; transtornos psiquiátricos anteriores, tais como: pânico, ansiedade generalizada, transtorno de conduta e de humor; familiares apresentando: TEPT, transtorno de humor e de conduta, além de dependência química; diferenças entre gêmeos serem mono ou dizigóticos e exposição ao combate.

Os resultados apontaram que, fatores de risco à exposição aos eventos traumáticos foram mais significativos nos indivíduos sob serviço militar na zona de combate do sudoeste da Ásia; esses indivíduos apresentaram preexistência de transtorno de conduta, dependência química e histórico familiar de transtornos do humor.

Para o desenvolvimento de TEPT, os fatores de risco apontados foram: indivíduos jovens, exposição a múltiplos traumas, depressão paterna, baixa escolari- dade ao entrarem no serviço militar, participação em combate, transtorno de conduta preexistente, pânico, ansiedade generalizada e depressão maior.

O estudo deixa claro algumas limitações: relações causais precisam ser melhores estudadas com outras metodologias e populações; o diagnóstico de TEPT não é tão fidedigno, pois só foram questionados três tipos de trauma aos sujeitos, deixando de abordar outras vivências traumáticas, excluindo possíveis situações e subestimando a prevalência de TEPT na população; não foi estudado possível co-morbidade com TEPT e não foram usados instrumentos de avaliação validados para a existência de transtornos psiquiátricos nos familiares e nas entrevistas com os gêmeos.

Apesar das limitações citadas, o trabalho é de relevância científica, pois demonstra a importância da presença de transtornos psiquiátricos, como o de conduta e de humor, tanto na exposição ao trauma como no risco em desenvolver TEPT. O diagnóstico de transtorno de conduta presente, tanto no indivíduo como nos familiares, leva a maiores chances de vivenciar eventos traumáticos e ao desenvolvimento de TEPT. Na depressão, a presença do transtorno em familiares é fator que pode determinar o desenvolvimento de TEPT.

Tal trabalho é de suma importância, pois indica a relevância dos fatores genéticos no desenvolvimento de TEPT e, somado a outros estudos preditivos, pode ser utilizado como referência no aprimoramento do tratamento preventivo à TEPT.

\footnotetext{
Referências bibliográficas

McFarlane, A.C. - Posttraumatic Stress Disorder: a Model of the Longitudinal Course and Role of Rick Factors. J Clin Psychiatry 61[supp15]: 15-20, 2000.

Kessler, R.C.; Sonnega, A.; Bromet, E. et al. - Posttraumatic Stress Disorder in the Nacional Comorbidity Survey. Arch Gen Psychiatry 52: 1048-60, 1995.
}

Psicóloga colaboradora do Ambulatório de Ansiedade (AMBAN).

Endereço para correspondência:

Instituto e Departamento de Psiquiatria da FMUSP

Rua Dr. Ovídio Pires de Campos s/n, São Paulo, SP - CEP 05403-010

Koenen, K.; Harley, R.; Lyons, M. et al.

Rev. Psiq. Clín. 30 (3):95, 2003 